\title{
A cb-type cytochrome-c oxidase terminates the respiratory chain in Helicobacter pylori
}

\author{
Kumiko Nagata, ${ }^{1}$ Sakura Tsukita, ${ }^{2}$ Toshihide Tamura' and \\ Nobuhito Sone ${ }^{2}$
}

\footnotetext{
1 Department of Bacteriology, Hyogo College of Medicine, 1-1, Mukogawa-cho, Nishinomiya 663, Japan

2 Department of Biochemical System Engineering, Kyushu Institute of Technology, lizuka, Fukuoka-ken 820. Japan
}

\author{
Author for correspondence: Nobuhito Sone. Tel: +81948297813. Fax: +81948297801. \\ e-mail: sone@bse.kyutech.ac.jp
}

\begin{abstract}
A Helicobacter pylori membrane fraction oxidized yeast and equine cytochrome $C$, and $N, N, N^{\prime}, N^{\prime}$-tetramethyl-p-phenylenediamine (TMPD). When ascorbate was used as reductant, the $V_{\max }$ and apparent $\boldsymbol{K}_{m}$ values were $612 \mathrm{nmol}$ electron $\mathrm{min}^{-1}$ ( $\mathrm{mg}$ protein) ${ }^{-1}$ and $14 \mu \mathrm{M}$ for yeast, and $419 \mathrm{nmol}$ electron $\mathrm{min}^{-1}$ (mg protein) ${ }^{-1}$ and $19 \mu \mathrm{M}$ for equine cytochrome $c$, respectively. For TMPD oxidation, the $V_{\max }$ and $K_{m}$ values were $640 \mathrm{nmol}^{\text {electron } \mathrm{min}^{-1}}$ ( $\mathrm{mg}$ protein) ${ }^{-1}$ and $182 \mu \mathrm{M}$, respectively. These oxidase activities showed a high affinity for oxygen. Inhibition of both cytochrome-c and TMPD oxidase activities by $50 \%$ was caused by about $4 \mu \mathrm{M}$ cyanide and about $0.5 \mathrm{mM}$ azide. Redox difference spectra of the membrane solubilized with Triton X-100 showed b- or c-type cytochromes but not aa $a_{3}$-type cytochromes. c-type and a part of some b-type cytochromes were reduced with ascorbate plus TMPD. A CO difference spectrum revealed that protohaem, but not an $\mathbf{a a}_{3}$-type cytochrome, may be interacting with CO/oxygen. Only protohaem was detected in the haem fraction extracted from the membrane. Three polypeptides (60, 38 and $29 \mathrm{kDa}$ ) were found to be bearing haem c after SDSPAGE of the membrane. From these results, it was suggested that the $\mathbf{c b b}_{\mathbf{3}}$ type cytochrome-c oxidase, having a haem-copper binuclear centre like the cytochrome $a a_{3}$-type oxidase, but differing in a few other properties, functions as a terminal oxidase in the respiratory chain of $\boldsymbol{H}$. pylori.
\end{abstract}

Keywords: Helicobacter pylori, microaerobic respiration, cytochrome-c oxidase

\section{INTRODUCTION}

Helicobacter pylori is a Gram-negative, microaerophilic, spiral bacterium that resides in the stomach of humans. This organism has been implicated as an essential factor or direct cause of gastritis, duodenal ulcers, and possibly neoplasia (Blaser, 1990; Marshall \& Warren, 1984; Parsonnet et al., 1991, 1994; Rabeneck \& Ransohoff, 1991). H. pylori lives in the mucous layer overlying the gastric epithelium of humans, where the microenvironment is low in oxygen because of rapid growth of the epithelium cells. $H$. pylori is an obligate aerobe which does not grow in the presence of normal air-oxygen pressure nor anaerobically in the absence of oxygen. $H$. pylori does not catabolize saccharides (Marshall et al., 1984; McNulty \& Dent, 1987), but derives energy from

Abbreviation: TMPD, $N, N, N^{\prime}, N^{\prime}$-tetramethyl-p-phenylenediamine. the metabolism of organic acids and amino acids via the Krebs cycle. $H$. pylori is oxidase positive and has been reported to have menaquinone- 6 and an unidentified quinone as respiratory quinones (Goodwin et al., 1986; Moss et al., 1990). However, the biochemical properties of the respiratory and oxidase systems of $H$. pylori have not been characterized.

In aerobic eubacteria, the cytochrome $a a_{3}$ or $c a a_{3}$-type cytochrome- $c$ oxidase (EC 1.9.3.1) is very similar to the mitochondrial enzyme with respect to its chromophores and the main subunits (subunits I-III) (Buse et al., 1989; Calhoun et al., 1993; Saraste et al., 1991; Sone \& Yanagita, 1982). During the past several years, atypical cytochrome$c$ oxidases such as $c b b_{3}, b a_{3}$ and $b o_{3}$-types, as well as quinoloxidizing terminal oxidases of the $a a_{3}$-type and $b o_{3}$ and $b d$ types, have been found. These oxidases, except for the $b d-$ type, have been shown to possess a haem (high-spin)copper $\left(\mathrm{Cu}_{\mathrm{B}}\right)$ binuclear centre, although species of haem can differ (see Garcia-Horsman et al., 1995 for review). 
Moreover, these oxidases have homologous amino acid sequences, at least in subunit $\mathrm{I}$, which bears the oxygenreducing binuclear centre and an electron-donating lowspin haem (Saraste \& Castresana, 1994).

Among the haem-copper oxidase superfamily, the $c b b_{3}$ type cytochrome- $c$ oxidases, found in Rbodobacter capsulatus (Gray et al., 1994), Rhodobacter sphaeroides (GarciaHorsman et al., 1994) and Bradyrbizobium japonicum (Preisig et al., 1993), seem to be a primitive group, closely related to NO reductase according to sequence similarity (Bott $e t$ al., 1992; Keefe \& Maier, 1993; Preisig et al., 1993). cbb $3^{-}$ type cytochrome oxidase appears to be produced as an adaptation to microaerobic conditions (Bott et al., 1992; Garcia-Horsman et al., 1994), and it contains subunits II and III with no homology to their counterparts in $a a_{3}$ type cytochrome-c oxidases (Preisig et al., 1993). The terminal oxidases belonging to the haem-copper superfamily are known to be inhibited by cyanide at a submicromolar order and to have a very low $K_{\mathrm{m}}$ for oxygen of a micromolar order (Garcia-Horsman et al., 1995). Here we report the characteristics of cytochrome-c oxidase activity and the absorption spectra of the membrane fraction of $H$. pylori grown under microaerobic conditions.

\section{METHODS}

Reagents. $N, N, N^{\prime}, N^{\prime}$-Tetramethyl-p-phenylenediamine (TMPD), trifluoroacetic acid, $o$-tolidine and $\mathrm{Na}_{2} \mathrm{~S}_{2} \mathrm{O}_{4}$ were from Wako Pure Chemical. NADH, equine heart and yeast ( $\mathrm{Sac}$ charomyces cerevisiae) cytochrome $c$, duroquinone and tetrachlorohydroquinone were purchased from Sigma. Menaquinone-4 and ubiquinone-1 were gifts from Eisai. Thermophilic bacterial PS3 cytochrome- $c$ oxidase was purified as described previously (Sone \& Yanagita, 1982). Beef-heart cytochrome-c oxidase (Orii et al., 1977) and Escherichia coli bo ${ }_{3}$-type quinol oxidase (Tsubaki et al., 1993) were kindly donated by $\mathrm{Dr}$ Y. Orii of Kyoto University, Japan, and by Dr T. Mogi and Professor Y. Anraku of the University of Tokyo, Japan, respectively.

Bacterial strain, growth conditions and preparation of a membrane fraction. H. pylori NCTC 11637 was used throughout the present work and was cultured on Skirrow's medium plates containing $7 \%(\mathrm{v} / \mathrm{v})$ defibrinated horse blood as described previously (Nagata et al., 1992). The cultures were incubated for $3 \mathrm{~d}$ at $37^{\circ} \mathrm{C}$ in a microaerophilic atmosphere $\left[\mathrm{O}_{2} / \mathrm{CO}_{2} / \mathrm{N}_{2}(5: 15: 80\right.$, by vol.) $)$. The cultured cells were harvested by centrifugation $\left(10000 \mathrm{~g}\right.$ for $10 \mathrm{~min}$ at $\left.4{ }^{\circ} \mathrm{C}\right)$, washed with PBS $(0.139 \mathrm{M} \mathrm{NaCl} ; 3 \mathrm{mM} \mathrm{KCl} ; 10 \mathrm{mM}$ sodium potassium phosphate) at $\mathrm{pH} 7.0$, and stored as a cell pellet at $-80^{\circ} \mathrm{C}$. A membrane fraction of $\mathrm{H}$. pylori was prepared as follows. The cell pellet was suspended in a preparation medium containing $0.25 \mathrm{M}$ sucrose, $10 \mathrm{mM} \mathrm{KCl}, 1 \mathrm{mM} 2$-mercaptoethanol, $0.1 \mathrm{mM}$ EDTA, $20 \mathrm{mM}$ Tris/maleate buffer ( $\mathrm{pH} 6.5$ ) and $10 \mathrm{mM}$ potassium phosphate buffer $(\mathrm{pH} \mathrm{6.8)}$, and the suspension was sonicated for $30 \mathrm{~s}$ four times on ice. After centrifugation $\left(10000 \mathrm{~g}, 20 \mathrm{~min}, 4^{\circ} \mathrm{C}\right)$ to remove cell debris, the supernatant was centrifuged $\left(100000 \mathrm{~g}, 90 \mathrm{~min}, 4^{\circ} \mathrm{C}\right)$, and the pellet was suspended in the preparation medium and used as the membrane fraction.

Assay of oxidase activity. Oxygen uptake was monitored with an oxygen electrode (YSI no. 4001) in a semi-closed cell. Various substrates were added to $2 \mathrm{ml}$ of reaction medium containing $10 \mathrm{mM} \mathrm{KCl}, 2 \mathrm{mM}$ MOPS buffer (pH 6.8) and the membrane fraction $(0 \cdot 1-1.0 \mathrm{mg}$ protein). When quinols were used, DTT (final concentration $2 \mathrm{mM}$ ) was added to the reaction medium. Each quinone was reduced with DTT in the medium for $5 \mathrm{~min}$, and the membrane fraction was added to start the reaction. The apparent activity due to autooxidation of each quinol and DT'T was subtracted. The $K_{\mathrm{m}}$ for oxygen was determined by recording traces of oxygen uptake in the medium with a very low concentration range of oxygen using a highsensitivity strip chart recorder (Yokokawa model 3066) as described previously (Sone \& Fujiwara, 1991a). The concentration dependence of cytochrome $c$ and TMPD was measured using a glass electrode with ascorbate as a final electron donor according to the following equation, as described previously (Nicholls \& Sone, 1984): sodium ascorbate $+\mathrm{H}^{+}+1 / 2 \mathrm{O}_{2} \rightarrow$ dehydroascorbate $+\mathrm{H}_{2} \mathrm{O}+\mathrm{Na}^{+}$. The net alkali formation was determined by back-titration with $10 \mathrm{mM} \mathrm{HCl}$. The reaction medium $(2 \mathrm{ml})$ comprised $10 \mathrm{mM} \mathrm{KCl}, 10 \mathrm{mM}$ sodium ascorbate and $2 \mathrm{mM} \mathrm{MOPS} / \mathrm{KOH}$ (pH 6.8).

Determination of concentrations giving $\mathbf{5 0} \%$ inhibition $\left(\mathrm{IC}_{50}\right)$. Inhibition of cytochrome- $c$ and TMPD oxidase activities by $\mathrm{KCN}$ and azide was assayed using a Beckman DU-700 spectrophotometer. The oxidation of yeast ferrocytochrome $c$ and TMPD was followed at 550 and $610 \mathrm{~nm}$, respectively. The reaction was initiated by adding $0.01 \mathrm{ml}$ of the membrane fraction to $0.5 \mathrm{ml}$ of the reaction medium containing $10 \mathrm{mM}$ MOPS/KOH buffer and an appropriate amount of reduced cytochrome $c$ or TMPD in a cuvette of $1 \mathrm{~cm}$ light path. Percentage inhibition was determined by the following equation: inhibition $(\%)=[$ (activity without inhibitors - activity with inhibitors) (activity without inhibitors) $\left.{ }^{-1}\right] \times 100 . \mathrm{IC}_{50}$ is the concentration of $\mathrm{KCN}$ or azide which gave $50 \%$ inhibition.

Measurement of absorption spectra. Redox difference and $\mathrm{CO}$ difference spectra were recorded with a Beckman DU-70 spectrophotometer using a $1 \mathrm{~cm}$ light-path microcuvette. The sample of solubilized membrane fraction was prepared as follows: membrane fraction (10-20 mg protein $\mathrm{ml}^{-1}$ ) was solubilized in $2 \%$ Triton $\mathrm{X}-100,0.4 \mathrm{M} \mathrm{NaCl}$ and $0.1 \mathrm{M}$ Tris/ $\mathrm{HCl}$ ( $\mathrm{pH} 8.0$ ) with a brief sonication and successive centrifugation at $10000 \mathrm{~g}$ for $10 \mathrm{~min}$. The supernatant was used for spectrophotometry. The pelleted materials was scarce, and did not show cytochrome colour. Amounts of cytochrome $b$ and $c$ were estimated from the redox difference spectrum using $\varepsilon_{\mathrm{mm}}$ (563-577 nm) of $14 \cdot 3$ and $\varepsilon_{\mathrm{mM}}(550-535 \mathrm{~nm})$ of $21 \cdot 0$, respectively (Williams, 1964). Dipyridine ferrohaemochrome analysis of the cytochromes was carried out according to the method of Berry \& Trumpower (1987).

Analysis of haem. Non-covalently bound haem groups were extracted with $\mathrm{HCl} /$ acetone (Weinstein \& Beale, 1983) and concentrated in ethyl acetate after several phase separations with $0 \cdot 1 \mathrm{M} \mathrm{NaCl}$. The extracted haem groups were analysed by reverse-phase chromatography with a $1 \mathrm{ml}$ resource TM PRC column (Pharmacia) and monitored with a Water's 490 multiwavelength photometer. The solvents were water and acetonitrile, both containing trifluoroacetic acid $(0.05 \%)$, and a gradient elution (30-100\%) was done as described previously (Sone \& Fujiwara, 1991b). Protohaem, haem $a$ and haem $o$ (with protohaem) were prepared from haemoglobin, beef-heart cytochrome- $c$ oxidase and $E$. coli $b o_{3}$-type quinol oxidase, respectively, and used as standards.

Other methods. SDS-PAGE was carried out according to the method of Laemmli (1970). Staining of gels for haem-dependent peroxidase was carried out with $o$-tolidine (Reid \& Ingledew, 1980). The amount of protein in samples was determined by a modified Lowry method (Markwell et al., 1981). 


\section{RESULTS}

\section{Cytochrome-c oxidase activity}

Table 1 gives typical $H$. pylori membrane fraction oxidase activity measurements with various saturating concentrations of substrate. The membrane fraction rapidly oxidized TMPD as well as cytochromes $c$ from yeast and equine heart. The membrane fraction oxidized succinate, malate, lactate and NADH, showing the presence of the respective membrane-bound dehydrogenases. The rate of oxidation of these substrates was slow by comparison with oxidase activity. More than $90 \%$ of NADH, succinate and malate oxidation was inhibited by antimycin A $(50 \mu \mathrm{M})$. Several quinols were also oxidized, but much more slowly. These results indicated the presence of a cytochrome- $c$ oxidase, rather than a quinol oxidase, as the dominant terminal oxidase in $H$. pylori.

Table 2 summarizes the kinetic parameters of $H$. pylori cytochrome oxidase. Yeast cytochrome $c$ was a better

Table 1. Oxidase activity in the $H$. pylori membrane fraction with various electron donors

\begin{tabular}{|c|c|c|}
\hline Substrate & $\begin{array}{l}\text { Concn } \\
(\mathrm{mM})\end{array}$ & $\begin{array}{l}\text { Oxygen uptake } \\
{\text { [nmol } \mathrm{min}^{-1}}^{\left.(\mathrm{mg} \text { protein })^{-1}\right]}\end{array}$ \\
\hline Yeast cytochrome $c^{*}$ & 0.045 & $294 \cdot 9$ \\
\hline Equine cytochrome $c^{*}$ & 0.045 & $264 \cdot 0$ \\
\hline TMPD* & 0.750 & $313 \cdot 3$ \\
\hline $\mathrm{NADH}$ & 0.5 & $14 \cdot 5$ \\
\hline $\begin{array}{l}\text { NADH with cytochrome } c \\
(40 \mu \mathrm{M})\end{array}$ & 0.5 & $14 \cdot 5$ \\
\hline Malate & $2 \cdot 0$ & $2 \cdot 7$ \\
\hline Succinate & $2 \cdot 0$ & $5 \cdot 7$ \\
\hline Lactate & $2 \cdot 0$ & $1 \cdot 9$ \\
\hline Menaquinol-4 & 0.2 & $6 \cdot 2$ \\
\hline Ubiquinol-1 & $0 \cdot 2$ & $3 \cdot 3$ \\
\hline Tetrachlorohydroquinol & $0 \cdot 15$ & $8 \cdot 3$ \\
\hline Duroquinol & $7 \cdot 5$ & $6 \cdot 5$ \\
\hline
\end{tabular}

* In the presence of sodium ascorbate (final concentration $10 \mathrm{mM}$ ).
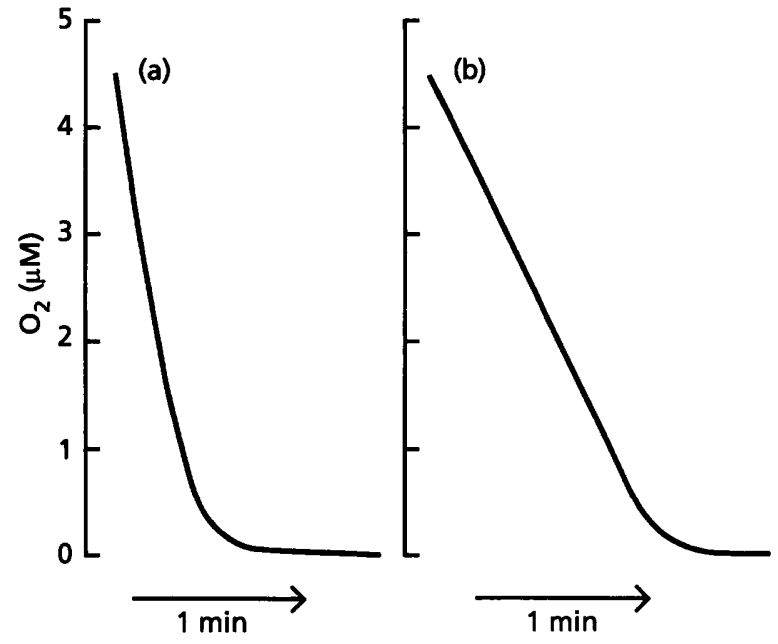

Fig. 1. Trace of TMPD oxidase activity of the membrane fraction of $H$. pylori (b) at a low oxygen concentration range compared with thermophilic bacterial PS3 cytochrome-c oxidase (a). About $50 \mu \mathrm{M}$ TMPD in the presence of $5 \mathrm{mM}$ ascorbate was used as an electron donor, and the other assay conditions were described in Methods.

substrate than equine cytochrome $c$. The concentration dependencies of the oxidase for these cytochromes $c$ showed sigmoidal-like curves (not shown). The activities at assumed real concentrations, with the adsorbed amounts subtracted (6 and $3 \mu \mathrm{M}$ for yeast and equine heart cytochrome $c$, respectively), followed Michaelis-Menten kinetics, and gave $K_{\mathrm{m}}$ values of $8 \mu \mathrm{M}$ for yeast cytochrome $c$ and $16 \mu \mathrm{m}$ for equine cytochrome $c$. TMPD was also oxidized rapidly without showing 'adsorption'. Both cytochrome- $c$ and TMPD oxidase activities were sensitive to inhibition by $\mathrm{KCN}$ and azide (Table 2 ).

We also measured the $K_{\mathrm{m}}$ for oxygen by following rates of oxygen uptake at a very low concentration range of oxygen with an oxygen electrode (Fig. 1). The $K_{\mathrm{m}}$ of the oxidase for oxygen was about $0.4 \mu \mathrm{M}$. The value is a little lower than that of the $a a_{3}$-type $(0.6 \mu \mathrm{M})$. The $\mathrm{pH}$ dependency of cytochrome- $c$ oxidase activity and its pattern was very similar to that of the mammalian

Table 2. Summary of oxidase activity kinetic parameters and its inhibition by $\mathrm{KCN}$ and azide in the $H$. pylori membrane fraction

\begin{tabular}{|lccc|}
\hline & \multicolumn{3}{c|}{ Substrate } \\
\cline { 2 - 4 } & Yeast cytochrome $c$ & Equine cytochrome $c$ & TMPD \\
\hline$V_{\text {max }}{ }^{*}$ & 612 & 419 & 640 \\
Apparent $K_{\mathrm{m}}(\mu \mathrm{M})$ & 14 & 19 & 182 \\
$\mathrm{IC}_{50}(\mu \mathrm{M})$ of $\mathrm{KCN}$ & 4 & - & $2 \cdot 5$ \\
$\mathrm{IC}_{50}(\mu \mathrm{M})$ of azide & 407 & - & 488 \\
\hline
\end{tabular}

$*_{\mathrm{nmol} \mathrm{min}}{ }^{-1}$ (mg protein $)^{-1}$. 


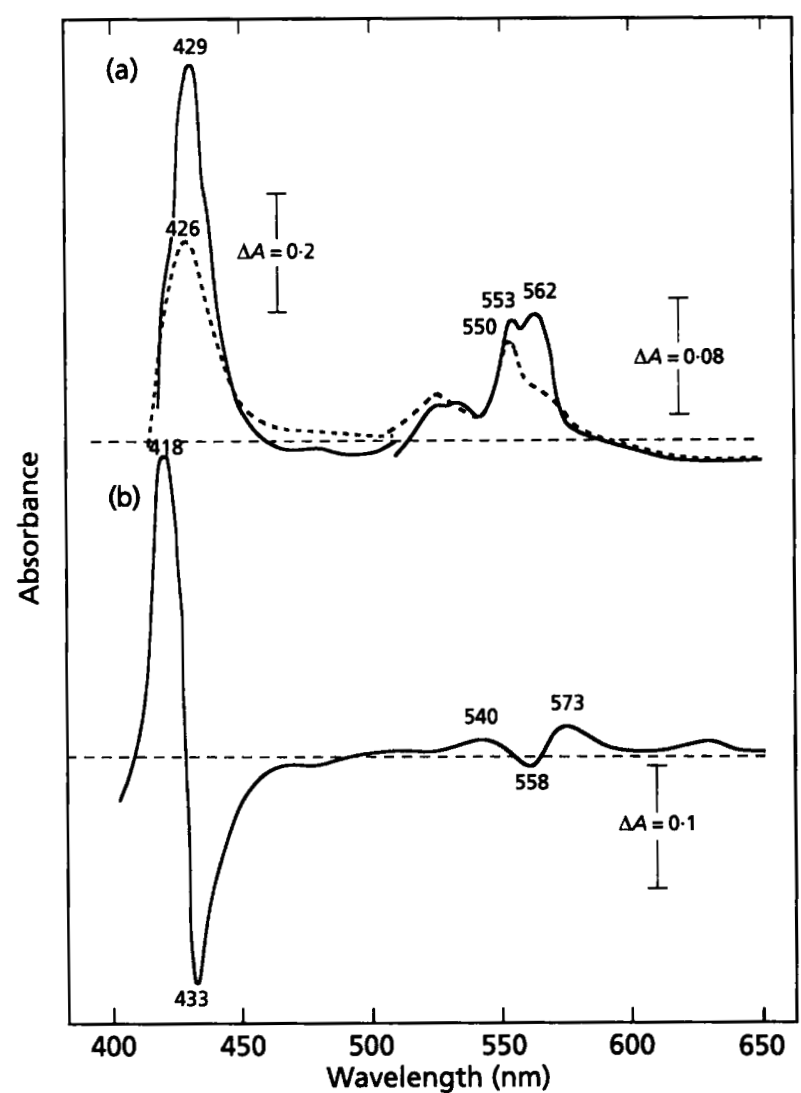

Fig. 2. Redox (a) and CO (b) difference spectra of the solubilized membrane fraction of $H$. pylori. The membrane (12.8 $\left.\mathrm{mg} \mathrm{ml}^{-1}\right)$ was solubilized as described in Methods. (a) --, Ascorbate (TMPD)-reduced minus oxidized; $\mathrm{Na}_{2} \mathrm{~S}_{2} \mathrm{O}_{4}$-reduced minus oxidized. (b) $\mathrm{Na}_{2} \mathrm{~S}_{2} \mathrm{O}_{4}$-reduced plus $\mathrm{CO}$ minus $\mathrm{Na}_{2} \mathrm{~S}_{2} \mathrm{O}_{4}$-reduced. For complete reduction, a very small grain of $\mathrm{Na}_{2} \mathrm{~S}_{2} \mathrm{O}_{4}$ was added in the presence of $5 \mathrm{mM}$ ascorbate and TMPD (below $10 \mu \mathrm{M}$ ).

mitochondrial enzyme (Orii \& Okunuki, 1965); the optimal $\mathrm{pH}$ was $5 \cdot 6-6 \cdot 0$, and moderate activities were observed at $\mathrm{pH} 7-8$ (not shown).

\section{Visible spectral properties}

Fig. 2(a) shows a reduced minus oxidized difference spectrum of a solubilized membrane fraction of $H$. pylori. Almost no absorption band was observed at around $600 \mathrm{~nm}$, indicating that cytochrome $a a_{3}$ is absent or is only a very minor component. Both $b$-type and $c$-type cytochromes were prominent upon reduction with $\mathrm{Na}_{2} \mathrm{~S}_{2} \mathrm{O}_{4}$ (continuous line), but only $c$-type cytochromes and a part of some $b$-type cytochromes could be reduced with ascorbate plus TMPD (dotted line). From the redox difference spectra, the cytochrome $c$ and $b$ content was calculated to be 0.2 and $0.5 \mathrm{nmol}$ per $\mathrm{mg}$ of $H$. pylori membrane fraction protein, respectively. These cytochrome levels in $H$. pylor $i$ are the same order as the levels found in many aerobes.

The CO difference spectrum (Fig. 2b) shows that the

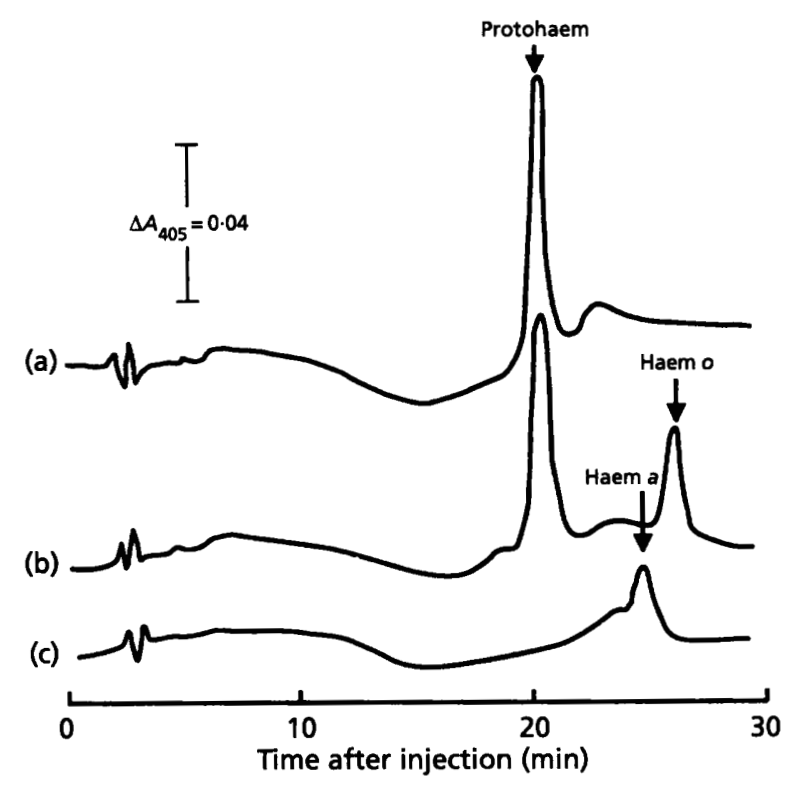

Fig. 3. Elution profiles of haem compounds after reverse-phase HPLC. (a) Haem fraction extracted from the $H$. pylori membrane fraction. (b) Haem fraction from $E$. coli bo b $_{3}$-type quinol oxidase containing protohaem and haem $O$. (c) Haem fraction from beef heart cytochrome-c oxidase containing haem $a$.

trough due to the $\gamma$ band of the reduced form is at $433 \mathrm{~nm}$, indicating that the CO-binding cytochrome is not cytochrome $a a_{33}$, but is of the $b$-type or 0 -type. A very similar difference spectrum was reported for CO-reactive cytochrome o (Puustinen \& Wikström, 1991; Sone \& Fujiwara, 1991a).

\section{Haem analysis}

Haem $o$ (2-hydroxyethylfarnesyl protohaem) constitutes the binuclear oxygen-reducing site as the high-spin haem in E. coli bo-type quinol oxidase (Puustinen \& Wikström, 1991) and Bacillus cytochrome-c oxidase cultured under microaerobic conditions (Sone \& Fujiwara, 1991a). The hydrophobicity of haem $o$ is similar to haem $a$, but its spectrum is similar to protohaem. In order to distinguish between haem $o$ and protohaem, the haem fraction was extracted from the $H$. pylori membrane preparation and analysed as shown in Fig. 3. Almost all the extracted haem was protohaem, and neither haem $o$ nor haem $a$ was present. Dipyridine ferrohaemochrome analysis of the extracted haem showed an $\alpha$ band at $557 \mathrm{~nm}$ to be the authentic protohaem (not shown).

$c$-type cytochromes have covalently bound haem $c$, and thus their distribution among the subunits of proteins can be analysed by a haem-staining procedure after SDSPAGE, by exploiting the intrinsic peroxidase activity of haem groups (Reid \& Ingledew, 1980). Fig. 4 shows a typical haem stain of the $H$. pylori membrane fraction. Three peroxidase-positive bands of apparent molecular mass 60,38 and $29 \mathrm{kDa}$ were found in the $H$. pylori 


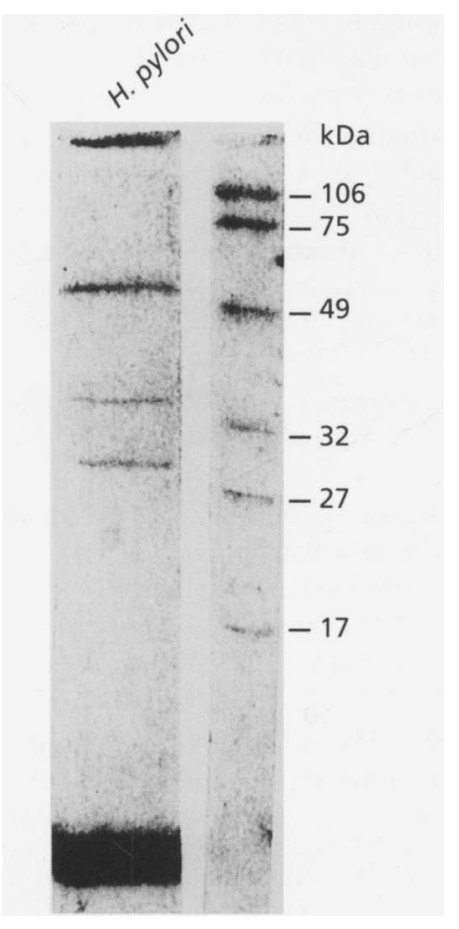

Fig. 4. Identification of c-type cytochromes of $H$. pylori after SDS-PAGE. $H$. pylori membrane protein $(43 \mu \mathrm{g})$ was separated by SDS-PAGE and stained for peroxidase activity as described in Methods. Bio-Rad prestained marker proteins $(106,75,49,32$, 27 and $17 \mathrm{kDa}$ ) were used.

membrane. It is noteworthy that no small c-type cytochrome was found in the $H$. pylori membrane fraction. On the contrary, a $c$-type cytochrome having an $\alpha$ band at $553 \mathrm{~nm}$ was found in the soluble fraction of $H$. pylori.

\section{DISCUSSION}

The present data using a membrane fraction of $H$. pylori clarified several characteristics of the respiratory chain and terminal oxidase of $H$. pylori: (1) cytochrome components were restricted to $b$ - and $c$-type; (2) CO difference spectra and analysis of haem components showed that protohaem is interacting with oxygen; (3) cyanide inhibited the cytochrome- $c$ and TMPD oxidase activities at a very low concentration; (4) the $K_{\mathrm{m}}$ for oxygen was low (about $0.4 \mu \mathrm{M}$ in the TMPD oxidation); (5) the terminal oxidase oxidized cytochrome $c$ not quinol; (6) three kinds of $c$ type cytochromes $(60 \mathrm{kDa}, 38 \mathrm{kDa}$ and $29 \mathrm{kDa}$ by SDSPAGE) were present in the $H$. pylori membrane fraction. These results strongly suggest that the terminal oxidase of $H$. pylori is a $c b b_{3}$-type cytochrome-c oxidase.

$H$. pylori is a strict microaerobe. The most suitable gaseous conditions for growth are 5-7\% oxygen and 7-10\% carbon dioxide in nitrogen. $H$. pylori lives in the mucous layer of the human stomach and can be associated with any part of the lumina of gastric-mucus-secreting cells but is most frequently sited in the 'grooves' at the junction of individual epithelial cells (Steer, 1989). In the environment of these 'grooves', the oxygen tension seems to decrease because epithelial cells in the human stomach grow very rapidly with a generation time of about $1 \mathrm{~d}$ (Lipkin et al., 1963). Thus, $H$. pylori grows to adapt to the microaerobic niche in vivo, and the $c b b_{3}$-type cytochrome$c$ oxidase with a high affinity for oxygen identified in the present study is well-suited for this environment. Bacteria of the genus Campylobacter, to which $H$. pylori formerly belonged, are also microaerophilic. Our preliminary results have shown that the terminal oxidase of Campylobacter jejuni is also a $c b b_{3}$-type cytochrome-c oxidase (authors unpublished observations). Cytochrome $(c) b b_{3}$ type oxidases may be widely found among microaerobic bacteria or those grown under microaerobic conditions. It has been shown that the $c b b_{3}$-type oxidase is induced under microaerobic conditions and that this oxidase is essential for nitrogen-fixing bacteroids (Preisig et al., 1993). Recently, this type of cytochrome-c oxidase was reported in the non-endosymbiotic photosynthetic bacteria R. capsulatus and R. sphaeroides when grown under microaerobic conditions (Garcia-Horsman et al., 1994; Gray et al., 1994).

SDS-PAGE analysis revealed that three $c$-type cytochromes with rather high apparent molecular masses $(60$, 38 and $29 \mathrm{kDa}$ ) were present in the H. pylori membrane fraction (Fig. 4). The $c b b_{3}$-type cytochrome oxidases from R. capsulatus, R. sphaeroides, B. japonicum and Azorbizobium caulinodans are reported to have two haem $C$ subunits (Garcia-Horsman et al., 1994; Gray et al., 1994; Keefe \& Maier, 1993; Mandon et al., 1994). Thus, the three proteins with haem $c$ in the $H$. pylori membrane fraction (Fig. 4) may be assignable to $c$-type cytochrome subunits of cytochrome $c b b_{3}$-type oxidase and cytochrome $b c_{1}$ complex. The molecular masses of two $c$-type cytochromes in $A$. caulinodans are reported to be $30.9 \mathrm{kDa}($ fixP) and $27.6 \mathrm{kDa}(f i x)$ ) (Mandon et al., 1994) and those in $R$. sphaeroides are estimated to be 35 and $29 \mathrm{kDa}$ (GarciaHorsman et al., 1994). Usually, cytochrome $c_{1}$ has a molecular mass of $26-33 \mathrm{kDa}$, but a Paracoccus denitrificans cytochrome $c_{1}$ has a molecular mass of about $62 \mathrm{kDa}$ (Berry \& Trumpower, 1985). One of these $c$-type cytochromes may be a component of the cytochrome $b c_{1}$ complex, and the rest seem to constitute cytochrome $c b b_{3}$ type oxidase. Some of the amount of the total $c$-type cytochromes $\left[0 \cdot 2-0 \cdot 3 \mathrm{nmol}(\mathrm{mg} \text { membrane protein })^{-1}\right]$ was comparable to the amount of high-spin protohaem which may react with oxygen/CO. If the peak in the $\gamma$ band of high-spin protohaem of reduced $c b b_{3}$ has an $\varepsilon_{\mathrm{mM}}$ of 150 at $433 \mathrm{~nm}$, its concentration is calculated to be $0.096 \mathrm{nmol}$ (mg protein) $)^{-1}$ from the difference spectra (Fig. 2b). It is thus likely that single high-spin protohaem is reacting with $\mathrm{CO}$, and two or three different $c$-type cytochromes constitute the terminal oxidase of $H$. pylori. Most of these $c$-type and $b$-type cytochromes may have high redox potentials and so can be reduced with ascorbate (Fig. 2a).

Compared to the high activities of cytochrome $c$ or TMPD oxidation, NADH oxidase activity was very low (Table 1). NADH oxidase activity determined spectro- 
photometrically and NADH-ferricyanide reductase activity in the $H$. pylori membrane fraction were also low (data not shown). The reason why the NADH dehydrogenase activity was so low in the membrane fraction is not known at present. Addition of cytochrome $c$ did not accelerate NADH oxidation (Table 1). However, FADcontaining type II NADH dehydrogenases, but not the membrane-intrinsic $\mathrm{H}^{+}$-pumping complex $\mathrm{I}$ (type I) enzyme, may detach from the membrane upon preparation (Sone, 1990), and these peripheral enzymes may reduce menaquinones of $H$. pylori. It is possible that the $H$. pylori membrane preparation is right-side out and NADH may not cross the membrane, since the preparation showed appreciable oxidase activities for cytochrome $c$ as well as membrane-permeable TMPD. However, bacterial membrane preparations derived by sonication seldom produce right-side out membrane vesicles, and in fact the addition of detergents, such as sucrose monolaurate and Triton X$100(0.1 \%$ in the reaction medium $)$ did not stimulate NADH oxidation.

\section{REFERENCES}

Berry, E. A. \& Trumpower, B. L. (1985). Isolation of ubiquinol oxidase from Paracoccus denitrificans and resolution into cytochrome $b c_{1}$ and cytochrome $c-a a_{3}$ complexes. $J$ Biol Chem 260, 2458-2467.

Berry, E. A. \& Trumpower, B. L. (1987). Simultaneous determination of hemes $a, b$, and $c$ from pyridine hemochrome spectra. Anal Biocbem 161, 1-15.

Blaser, M. J. (1990). Helicobacter pylori and the pathogenesis of gastroduodenal inflammation. J Infect Dis 161, 626-633.

Bott, M., Preisig, O. \& Hennecke, H. (1992). Genes for a second terminal oxidase in Bradyrbizobium japonicum. Arch Microbiol 158, 335-343.

Buse, G., Hensel, S. \& Fee, J. A. (1989). Evidence for cytochrome oxidase subunit I and a cytochrome $c$-subunit II fused protein in the cytochrome ' $c_{1} a a_{3}$ ' of Thermus thermophilus. Eur J Biochem 181, 261-268.

Calhoun, M. W., Hill, J. J., Lemieux, L. J., Ingledew, W. J., Alben, J. O. \& Gennis, R. B. (1993). Site-directed mutants of the cytochrome bo ubiquinol oxidase of Escherichia coli: amino acid substitutions for two histidines that are putative $\mathrm{Cu}_{B}$ ligands. Biochemistry 32, 11524-11529.

Garcia-Horsman, J. A., Berry, E., Shapleigh, J. P., Alben, J. O. \& Gennis, R. B. (1994). A novel cytochrome $c$ oxidase from Rhodobacter sphaeroides that lacks $\mathrm{Cu}_{\mathrm{A}}$. Biochemistry 33, 3113-3119.

Garcia-Horsman, J. A., Barquera, B., Rumley, M. J. \& Gennis, R. B. (1995). The superfamily of heme-copper respiratory oxidases. $J$ Bacteriol 176, 5587-5600.

Goodwin, C. S., Collins, M. D. \& Blincow, E. (1986). The absence of thermoplasmaquinones in Campylobacter pyloridis, and its temperature and $\mathrm{pH}$ growth range. Microbios Lett 32, 137-140.

Gray, K. A., Grooms, M., Myllykallio, H., Moomaw, C., Slaughter, C. \& Daldal, F. (1994). Rhodobacter capsulatus contains a novel $c b$-type cytochrome $c$ oxidase without a $\mathrm{Cu}_{\mathrm{A}}$ center. Biochemistry 33, 3120-3127.

Keefe, R. G. \& Maier, R. J. (1993). Purification and characterization of an $\mathrm{O}_{2}$-utilizing cytochrome- $c$ oxidase complex from $\mathrm{Brady}$ rbizobium japonicum bacteroid membranes. Biochim Biopbys Acta 1183, 91-104.

Laemmli, U. K. (1970). Cleavage of structural proteins during the assembly of the head of bacteriophage T4. Nature 227, 680-685.
Lipkin, M., Sherlock, P. \& Bell, B. (1963). Cell proliferation kinetics in the gastrointestinal tract of man. II. Cell renewal in stomach, ileum, colon, and rectum. Gastroenterology 45, 721-729.

Mandon, K., Kaminski, P. A. \& Elmerich, C. (1994). Functional analysis of the fixNOQP of Azorbizobium caulinodans. J Bacteriol 176, 2560-2568.

Markwell, M. A. K., Haas, S. M., Tolbert, N. E. \& Bieber, L. L. (1981). Protein determination in membrane and lipoprotein samples: manuals and automated procedures. Methods Enzymol 72, 1920-1931.

Marshall, B. J. \& Warren, J. R. (1984). Unidentified curved bacilli in the stomach of patients with gastritis and peptic ulceration. Lancet i, 1311-1314.

Marshall, B. J., Royce, H., Annear, D. I., Goodwin, C. S., Pearman, J. W., Warren, J. R. \& Armstrong, J. A. (1984). Original isolation of Campylobacter pyloridis from human gastric mucos. Microbios Lett 25, 83-88.

McNulty, C. A. \& Dent, J. C. (1987). Rapid identification of Campylobacter pylori (C. pyloridis) by preformed enzymes. J Clin Microbiol 25, 1683-1686.

Moss, C. W., Lambert-Fair, M. A., Nicholson, M. A. \& Guerrant, G. O. (1990). Isoprenoid quinones of Campylobacter cryaerophila, $C$. cinaedi, $C$. fennelliae, $C$. byointestinalis, $C$. pylori, and ' $C$. upsaliensis'. J Clin Microbiol 28, 395-397.

Nagata, K., Mizuta, T., Tonokatu, Y., Fukuda, Y., Okamura, H., Hayashi, T., Shimoyama, T. \& Tamura, T. (1992). Monoclonal antibodies against the native urease of Helicobacter pylori: synergistic inhibition of urease activity by monoclonal antibody combinations. Infect Immun 60, 4826-4831.

Nicholls, P. \& Sone, N. (1984). Kinetics of cytochrome $c$ and TMPD oxidation by cytochrome $c$ oxidase from the thermophilic bacterium, PS3. Biochim Biopbys Acta 767, 240-247.

Orii, Y. \& Okunuki, K. (1965). Studies on cytochrome a. XV. Cytochrome oxidase activity of the okunuki preparation and its activation by heat, alkali and detergent treatments. $J$ Biochem 58, 561-568.

Orii, Y., Manabe, M. \& Yoneda, M. (1977). Molecular architecture of cytochrome oxidase and its transition on treatment with alkali or sodium dodecyl sulfate. J. Biochem 81, 505-517.

Parsonnet, J., Friedman, G. D., Vandersteen, D. P., Chang, Y., Vogeiman, J. H., Orentreich, N. \& Sibley, R. K. (1991). Helicobacter pylor $i$ infection and the risk of gastric carcinoma. N Engl J Med 325, 1127-1131.

Parsonnet, J., Hansen, S., Rodriguez, L., Gelb, A. B., Warnke, R. A., Jellum, E., Orentrich, N., Vogelman, J. H. \& Friedman, G. D. (1994). Helicobacter pylori infection and gastric lymphoma. N. Engl J Med 330, 1267-1271.

Preisig, O., Anthamatten, D. \& Hennecke, H. (1993). Genes for a microaerobically induced oxidase complex in Bradyrbizobium japonicum are essential for a nitrogen-fixing endosymbiosis. Proc Natl Acad Sci US A 90, 3309-3313.

Puustinen, A. \& Wikstrom, M. (1991). The heme groups of cytochrome 0 from Escherichia coli. Proc Natl Acad Sci US A 88, 6122-6126.

Rabeneck, L. \& Ransohoff, D. F. (1991). Is Helicobacter pylori a cause of duodenal ulcer? A methodologic critique of current evidence. Am J Med 91, 566-572.

Reid, G. A. \& Ingledew, W. J. (1980). The purification of a respiratory oxidase complex from Escherichia coli. FEBS Lett 109, $1-4$.

Saraste, M. \& Castresana, J. (1994). Cytochrome oxidase evolved by tinkering with denitrification enzymes. FEBS Lett 341, 1-4. 
Saraste, M., Metso, T., Nakari, T., Jalli, T. M., Lauraeus, M. \& Van der Oost, J. (1991). The Bacillus subtilis cytochrome $-c$ oxidase. Variations on a conserved protein theme. Eur J Biochem 195, 517-525.

Sone, N. (1990). Respiration-driven proton pumps. In Bacterial Energetics, pp. 1-32. Edited by T. A. Krulwich. London: Academic Press.

Sone, N. \& Fujiwara, Y. (1991a). Haem O can replace A in the active site of cytochrome $c$ oxidase from thermophilic bacterium PS3. FEBS Lett 288, 154-158.

Sone, N. \& Fujiwara, Y. (1991b). Effects of aeration during growth of Bacillus stearotbermophilus on proton pumping activity and change of terminal oxidase. J Biochem 107, 597-602.

Sone, N. \& Yanagita, Y. (1982). A cytochrome $a a_{3}$-type terminal oxidase of a thermophilic bacterium. Purification properties and proton pumping. Biochim Biophys Acta 682, 216-226.

Steer, H. W. (1989). Ultrastructure of Campylobacter pylori in vivo.
In Campylobacter pylori and Gastroduodenal Disease, pp. 146-154. Edited by B. J. Rathbone \& R. V. Heatley. London: Blackwell Scientific Publications.

Tsubaki, M., Mogi, T., Anraku, Y. \& Hori, H. (1993). Structure of the heme-copper binuclear center of the cytochrome bo complex of Escherichia coli: EPR and fourier transform infrared spectroscopic studies. Biocbemistry 32, 6065-6072.

Weinstein, J. D. \& Beale, S. I. (1983). Separate physiological roles and subcellular compartments for two tetrapyrrole biosynthetic pathways in Euglena gracilis. J Biol Chem 258, 6799-6807.

Williams, J. N., Jr (1964). A method for the simultaneous quantitative estimation of cytochromes $a, b, c_{1}$, and $c$ in mitochondria. Arch Biochem Biopbys 107, 537-543.

Received 24 October 1995; revised 10 February 1996; accepted 23 February 1996. 